\title{
DISCLAIMER
}

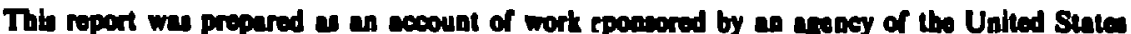

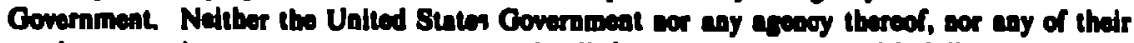

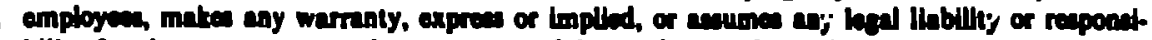

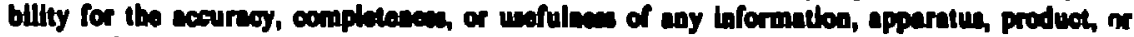

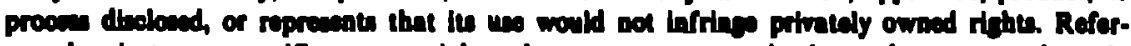

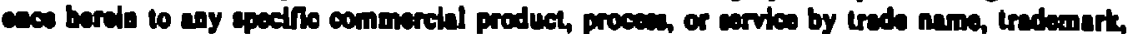

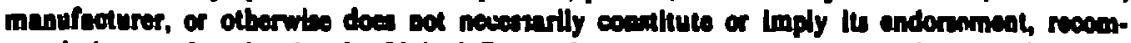

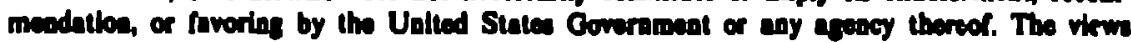

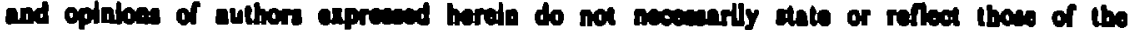
Unitid Stules Covorameat of any apocoy thereof. 


\section{LASER DIAGNOSTICS OF MATERIALS AND CHEMISTRY}

Allen Hartiord Jr.

Chemistry Division, Los Alamos National Laboratory, Los Alamos, MY 87545, USA

\section{INTRODUCTION}

Substantial effort has been directef toward understanding high temperature phenomens. A particularly challenging problem has been to characterize the chemical and physical processes which occur at elevated tenperatures and are not predictable by extrapolation from lower temperature data. In recent years the study of high temperature processes has been facilitated by developments in instrumentation and measurement techniques. Among the promising diagnostic methods that have emerged are those based on advances in laser spectroscopy. Numerous Jaser-based diagnostic techniques have been demonstrated that simultaneously provide high spatial, temporal, and spectroscopic resolution and: perhaps more importantly, allow nonintrusive interrogation of the systems under investigation. These attributes have permitted real-time in situ detection and messurement of atomic and molecular species in such hostile environments as flames, ${ }^{1-8}$ internal combustion engines, ${ }^{9,10}$ plasmas, ${ }^{11,12}$ and cosl gasifiers. ${ }^{13}$ In addition, laser techniques have proven quite verstalle for studying the kinetics and mechanisms of chemical reactions. ${ }^{14-20}$ Species typically encountered in high temperature processes can be readily produced under well-controlled conditione by laser photolysis of suitable materials. The subsequent temporal evolution of the species thus produred may then be followed by various laser diagnostics. This approach has yielded much fundamental information concerning state-selected chemical reactions. Yet other novel laser techniques have been used to atudy mulecular lons ${ }^{21-23}$ and metal clusters, ${ }^{24-2.6}$ species often present in high temperature processes. 
The: number of laser diagnostics and their applications to high-temperature processes are far too vast to review in the present discussion. Rather by describing some recent investigations, the versatility of laser diagnostics and their possibie extension to other applications will be apparent.

\section{APPLICATION OF LASERS TO CHEMICAL ANALYSIS}

One of the basic challenges of high-temperature science is to understand the chemical cumposition of systems under extreme conditions. Sampling techniques coupled with conventional analytical procedures (e.g. gas chromatograph, absorption spectroscopy, wet chemistry) often fail to provide adequate spatial and temporal information. As a consequence, much vital information concerning concentration fluctuations and the presence of unusual intermediates can be lost.

Significent advances in the ability to make noninvasive in situ measurements with eacellent spatial and temporal resolution have resulted from the development of laser spectroscopic; techniques. Among the laser diagnostic techniques that possess these attributes and that have been successfully applied in a number of applications ale laser-induced fluorescence (LIF), laser-induced breakdown spectroscopy (LIBS), 27,28 and coherent anti-Stokes Raman scattering (CARS) and its variants such as BOXCARS. ${ }^{29}$ To date these techniques have been primarily employed to monitor gaseous media, although examples of applications to liquids and solids also exist. The predoninant high-temperature application of laser diagnostics has been in the study of conbustion. phenomena.

Recently, wi: have evaluated ond tested several laser diaguostics for on-line: chemical analysis in two rather different industrial processes: coal gasification and steel production. In the former application there is need to rapidly monitor the product gas te ensure that it is of the appropriate composition (1.e., is of the currect heating value) and that toxic or corrosive contaminants have been 
reduced to acceptable levels. During the manufacture of steel rapid on-line analyses would improve productivity, lead to better consistency in product quality, and result in reduced energy consumption.

Real-time, full-flow monitoring of the composition of coal gasifier streams poses a severe test of optical instrumentation. Depending on the particular gasification process involved, pressures typically exceed $10 \mathrm{~atm}$, temperatures of $1000 \mathrm{~K}$ are common, and the gas streams can be ladened with particulates and heavy hydrocarbons (tars). Consequently, optical transmission and resulting signal levels can be severely degraded. In spite of these limitations a CrRS apparatus has been successfully implemented on a stirred, fixed-bed coal gasifier located at the Morgantown Energy Technology Center (METC) in Morgantown, West Virginia. Both major and minor constituents of the process stream were measured in real-time ( $\sim 2-s$ temporal resolution). In addition $L I B S$ has been used to identify numerous corrosive and toxic elements within the gasifier process stream. By virtue of the rapid temporal response of these diagnostics, both may ultimately have application to active contro] of the gasification and cleanup processes.

Coherent anti-Stokes Riman scattering is a fnuz-wave mixing process that occurs when two incident laser beams interact through the third-order nonlinear susceptibility of a material and produce coherent radiation at a frequency $w_{3}=2 w_{1}-w_{2} \cdot 30$ The frequencies $w_{1}$ and $w_{2}$ are generally referred to as the punp ard Stokes frequencies, respectively. When the frequency difference belween $w_{l}$ and $w_{2}$ corresponds to the frequency of a Raman-active mode in the material veing probed, a resonant enhancement occurs. The CARS process is an intensity-dependent effect, being proportional to $I_{1}{ }^{2} I_{2}$, where $I_{1}$ and $I_{2}$ are the intensities of the beams at $w_{1}$ and $w_{2}$, respectively. Because of this incensicy dependence, most cars stuilies have been performed with pulsed laners. A diagram of a typical CARS 
monitoring system is shown in Fig. 1. The pump wavelength $(532 \mathrm{~nm})$ is the frequencydoubled output from a pulsed Nd:YAG laser. A portion of the $532-\mathrm{nm}$ beam is used to pump a tunable dye laser which provides the Stokes beam.

Our CARS measurements on the METC gasifier were made at a location immediately following the reaction vessel and a cyclone. At this location the gas stream was at hign-temperature and high-pressure and contained significant levels of tars and particulates. This environment resulted in strong optical scattering of the laser beams which precluded a measurement of the absolute energy in the anti-Stokes beam $\left(w_{3}\right)$. As a consequence, we were only able to measure relative molfoular densities by separating the anti-Stokes beam from the input beams using a $0.5-\mathrm{m}$ monochromator. Ratios of concentrations were determined relative to $\mathrm{N}_{2}$, a gasificr constituent which due to its chemical inertness is not expected to vary.

The CARS signals from $\mathrm{N}_{2}$ and $\mathrm{CO}$ in the METC gasifier are shnwu in Figs. 2 and 3 , respectively. In each case the spectra on the right were obtained by scanning the tunable dye laser through the uand contour, while the signais on the left were obtained as a function of time with the dye laser fixed at the CARS peak. To obtain the ratio of $\mathrm{CO}$ to $\mathrm{N}_{2}$ from the CARS data, it was necessary to estimate the CARS susceptibilities from tabulated spontaneous Raman line strengths and the linewidths obtained from the gasifier scans. The relationship is given by

$$
\frac{x(C O)}{x\left(N_{2}\right)} \approx \frac{S(C O) / \Delta v(C O)}{S\left(N_{2}\right) / \Delta v\left(\bar{N}_{2}\right)}
$$

where $X$ is $t$ ' s susceptibility, $S$ the spontaneous Raman line strength, and $\Delta v$ the linewidth. The concentration atio obtained in this manner was $[\mathrm{CO}] /\left[\mathrm{N}_{2}\right]=0.34$. In on independent gas chromatographic ( $\mathrm{gC}$ ) measurement the $\mathrm{N}_{2}$ concentiation was found to be $46 \%$, which upon substitution in our ratio yields a co concentration of $17 \%$. The gc value for $C O$ was $23 \%$. Sources of uncertaunties in the CARS determination include tempural fluctuations in the peak CARS signals and variations in the CARS linewidths. 
Comparison of the time behavior of the peak CARS signals of $\mathrm{CO}$ and $\mathrm{N}_{2}$ reveals that CO signal fluctuations are twice as large as those observed for $\mathrm{N}_{2}$. Since the signal-to-noise ratio should be comparable in both cases, it appears that the $\mathrm{CO}$ fluctuations are indicative of true concentration fluctuations.

In addition to $\mathrm{N}_{2}$ and $\mathrm{CO}, \mathrm{H}_{2} \mathrm{~S}$ and $\mathrm{CH}_{4}$ have been detected in the METC gasifier. The CARS signal from $\mathrm{H}_{2} \mathrm{~S}$ is shown $\mathrm{in}$ Fig. 4, from which a concentration of $0.22 \%$ was computed. The methane signal is displayed in Fig. 5. The $\mathrm{CH}_{4}$ CARS spectrum exhibits the prominent Q-branch, as well as a red-shifted tail. The frequency of the tail correlates well with an expected hot band $[(0,0,0,1) \rightarrow(1,0,0,1)]$, but the shape is not as anticipated. The $\mathrm{CH}_{4}$ hot band may provide a struightforward inethod for temperature measurement. Most temperature determinations by CARS have utilized comparisons between experimental and computer simulated $\mathrm{N}_{2}$ band contours, ${ }^{31,32}$ an approach that works well at pressures up to $1 \mathrm{~atm}$. However, at higher pressures for which pressurebroadened widths of Q-branch rotational lines become comoarable to their spacing, collisional narrowing occurs. ${ }^{33}$ As a consequence of this phenomenon, at pressures up to $100 \mathrm{a}$ 'm the overall Q-branch width does not. chang: appreciably. Furthermore, neither the theory for collisional narrowing nor the CARS data base tave been extended to high pressure and tomperature conditions. Consequently, it is not yet possible to derive accurate gasilier temperatures from the $\mathrm{N}_{2}$ CARS spectia. We plan to evaluate temperature measurements based on both the $\mathrm{N}_{2}$ rotational structure and the $\mathrm{CH}_{4}$ vibrat.ional structure.

Ilisturically, the pres-nce of certain toxic and corrosive materials $(\mathrm{Na}, \mathrm{K}, \mathrm{Ba}$, $\mathrm{Co}, \mathrm{Mg}$, Se, $\mathrm{As}, \mathrm{Cd}, \mathrm{Pb}$, etr.) in the process streams of coal gasifiers has been difficult to detect. Furthermore, the form in which chese materials exist (i.e. elemental, molecular, or contained in particulates) in many cases is not well established. In the combustion of coal-derived gas to drive turbines, gas-solid corrosion reactions can result in severe iamage to the turbine blades if elenents such as the alkali metals are not maintained at acceptable levels. 
Laser-induced breakdown spectroscopy has proven to be a versatile technique for inonitoring toxic and corrosive materials in coal gasifiers. In LIBS, the output beam of a pulsed laser is focused into the material under investigation. At sufficiently high irradiances $\left(10^{8}-10^{9} \mathrm{~W} / \mathrm{cm}^{2}\right.$ for air at atmospheric pressure) a dielectric breakdown occurs and a luminous plasma is produced. Molecules and aerosols in the plasma volume are reduced to highly excited aioins. It is the characteristic emission spectra that permits detection and indentification of particular atoms.

A schematic of a typical LIBS apparatus is shown in Fig. 6. The plasma is generated by the focused output of a Nd:YAG laser. The emission from the plasma is dispersed and detected with a spectrometer equipped with a time-gated diode array. The gating allows introduction of a time-delay becween plasma initiation and spectral recording which results in an improved signal-to-noise ratio (SNR). The ejrly portion of the plasma is dominated by a strong continum emission which decays rapidly. On the other hand, emission from neutral atoms persists fox a much longer time. Consequently, by delaying observation until the continuum has decayed in intensity provides a substantial enhancement of the SNR.

A LIBS apparatus was installed on the METC coal zasifier. A single-ended optical configuration was employed in which a mirror placed at $45^{\circ}$ with respect to the laser bean both transmitted the $1.06-\mu m$ radiation and imaged the breakdown spot on the spectrometer slit. Spectra were recorded uver the spectral interval from $300 \mathrm{~nm}$ to $900 \mathrm{~nm}$. Typical spectra are shown in Fizs. 7 and 8 . Analysis of the spectra revealed that emission from $\mathrm{C}, \mathrm{H}, \mathrm{O}, \mathrm{N}, \mathrm{Cr}, \mathrm{Cu}, \mathrm{Fe}, \mathrm{Mg}, \mathrm{Pb}, \mathrm{S}$, and Se was consistently reproducible and exhibited many-line signatures. Emiszion from the elements $\mathrm{K}, \mathrm{Ca}$, $\mathrm{Cd}, \mathrm{Mn}, \mathrm{Al}, \mathrm{Ba}$, and $\mathrm{Li}$ was observed oniy periodically. This latter behavior was suggestive of breakdown of particulates which traverse the laser focal volume on a random basis. 
The current method for determining the composition of a stael melt utilizes conventional spark spectroscopy. A sample is withdrawn fron the melt, allowed to solidify, and finally incorporated as an electrode in a conventional spark source. The elapsed time between sample extraction and quantative analysis by spark spectroscopy is typically 5 to 10 minutes.

The concept of using lasers for rapid on-line spectrochemical analysis of metal samples was initially explored during the 1960's.34,35 Although some investigations have involved probing the surface of molten metal directly, ${ }^{36}$ this approach appears to have some practical difficulties for on-line analysis of steel samples. One problem simply involves optical access to the surface of the molten steel which is covered by a layer of slag. Even if a direct surface probe could be designed, the vapor above the surface could have a substantially different composition then the melt, thereby distorting the analysis. Consequently, we have chosen an approach that involves extracting a sample and allowing it to solidify prior to analysis. Two alterrative analytical procedures are being evaluated, one using a direct breakdown on the metal surface, the other employing a laser to merely generate a fine aerosol which is then transported by a carrier gas to an inductively coupled plasma (ICP) for spectral analys is .

The upparatus used for direct spark analysis using LIBS is depicted in Fig. 9. Initij!ly calibration curves were obtained by irradiating steel samples containing a hnown amount of the element of interest and plotting the emission intensity from a particular atomic transition versus concentration. As an example, six sapples of steel containing differing amounts of sulfur were analyzed five times each. Relative standard deviations were calculated and found to range from $28 \%$ at $0.033 \%$ sulfur to $5.7 \%$ at sulfur concentration of $0.52 \%$. Using this approach curves were developed for a number of elements and the detection limits established. These are presented in Table I. 
TABLE I

DETECTION LIMITS OF ELEMENTS IMPORTANT IN STEEL OBTAINED

BY DIRECT LASER-GENERATED SPARK ANALYSIS

Element

Carbon

Sulfur

Phosphorus

Molybdenum

Manganese

Nickel

Chromium

Silicon.

Titanium

Niobium

Vanadium
Detection

Limit

(\%)

0.054

0.03

0.79

$>0.2$

0.2

0.08

0.067

0.051

0.01

$>0.066$

0.022 
The laser ablation of steel particles into an ICP for spectrochemical analyses has the potential for greater detection sensitivity than direct LIBS. The apparalus is shown in Fig. 10. A polychromator allows simultaneous monitoring of several elements. Calibration curves were developed in a manner similar to that used for LIBS, except that the emission intensity from the element of interest was ratioed to the intensity of a line emanating from singly ionized iron $(271.4 \mathrm{~nm})$. A typical calibration curve is shown in Fig. 11. Current detection limits using the lajer ablation/ICP approach are provided in Table II. Comparison of these detection limits with those obtained by direct laser breakdown indicates that the laser ablation/ICP analysis in generai provides a greater sensitivity.

\section{HIGH-TEMPERATURE CHEMICAL KINETIC MEASUREMENTS}

Information concerning the temperature dependence of reaction rate constants is ciucial for assessing the importance of various chemical reactions occurring in hightemperature processes. It is well known that an Arrhenius extrapolation of lower temperature data often fails to reproduce the observed high temperature behavior. Consequently, to permit reliable extrapolations the determination of race constants over a meaningful temperature regime is necessary. Furthermore, since electronically or vitrationally excited species may react with different rates and produce different products than when in the ground state, state selective measurements are of importance.

The coupling of ldser photolytic techniques for producing transient molecular species with highly sensitive laser-induced fluorescence (LIF) detection has permitted detailed kinetic studies of specific reactions under well-controlled conditions. A schematic diagram of a typical apparatus for perfurning such measurements is shown in Fig. 12. The speries whose reactions we wish to scudy is generally produced by 
TABLE II

DETECTION LIMITS OF ELEMENTS IMPORTANT IN STEEL OBTAINED BY LASER ABLATION/ICP ANALYSIS

Element

Sulfur

Phosphorus

Molybdenum

Mangane': e

Nickel

Chromium

Silicon

Titaniun

Vanadium

$T$ in

Copper

Aluminu

Cobalt
Detection

Limit

(z)

0.02

0.25

0.039

0.2

0.04

0.067

0.051

0.02

0.022

0.01

0.038

0.009

0.014 
excimer laser photolysis of a suitable precursor molecule. A tunable probe laser is then used to excite fluorescence in the transient. Because the fluorescence intensity is proportional to the molecular concentration, by varying the delay time between the photolysis and probe laser pulses the temporal evaluation of the species concentration can be followed. In the presence of reactant gases this approach yields valuable kinetic information.

Recently, we have incorporated a high temperaturs cell into the laser photolysis/laser fluorescence apparatus. This cell (Fig. 13) is based on the design of Felder and coworkers ${ }^{37}$ and is capable of operation in the range from 298-1300 K. A central high-purity alumina tube is heated resistively in two zones by $\mathrm{Pt} / 40 \% \mathrm{Rh}$ resistance wire. Thermal insulation is provided by an alumina heat shield surrounded by zirconia fiber insulation, with the whole assembly enclosed in a water-cooled brass vacuum chamber. The temperature is measured by thermocouples inserted through 0 -ring seals to probe various regions of the oven. The thermocouple outputs are sent to a Micricon microprocessor which automatically regulates the heater current. The reactant and buffer gases are introduced at the bottom of the cell and are heated as they flow slowly $(\sim 0.15 \mathrm{~s} \mathrm{~m})$ through the center tube. A small amount of radical precursor in a helium aixture is introduced via a water-cooled variable length inlet system within a few centimeters of the optical ports to minimize pyzolysis and prereaction problems. The pressure is measured with a capacitance manometer and gas flows with calibrated Tylan mass flow meters. The gas flow in sufficiently fast to assure a fresh gas mix for each laser shot.

The initial reaction studied using the high temperature fluorescence cell involved that between $C_{2}$ and $O_{2} . C_{2}$ is known to exist in large concentrations in high cemperatue processes such as combustion. Furthermore, existence of a low lying electronic state $\left(a^{3} \Pi_{u}\right)$ within $610 \mathrm{~cm}^{-1}$ of the ground state $\left(x^{1} \Sigma_{g}^{+}\right)^{38}$ means that both states will be populated at temperatures of interest. 
Both $c_{2}\left(x^{1} \Sigma_{8}^{+}\right)$and $c_{2}\left(a^{3} \Pi_{u}\right)$, henceforth denoted by ${ }^{1} c_{2}$ and ${ }^{3} c_{2}$, respectively, are produced upon the 193-nm multiple-photon dissociation of perfluorobutyne $\left(\mathrm{CF}_{3} \mathrm{CCCF}_{3}\right)$. Addition of gpproxi' itely 20 torr cf He to the 1-2 mtorr of the precursor assures that the $C_{2}$ produced is translationally and rotaticnally thermalized. However, this pressure of helium does not efrectiveiy quench the vibrational excitation.

The ${ }^{3} c_{2}$ was monitored by exciting the $(0,0)$ band of the swan bands $\left(d^{3} \Pi_{g}+a^{3} \Pi_{u}\right)$ at $516 \mathrm{~nm}$ and observing fluor scence from the $(0,1)$ transition at $564 \mathrm{~nm}$. Vibracionally excited ${ }^{3} c_{2}$ was probed either by exciting the $(v, v)$ transition in the Swan bands and monitoring fluorescence on the $(v, v+1)$ band or by exciting the $(v-1, v)$ band while detecting fluorescence from $(v-1, v-1)$. To monitor the fate of ${ }^{1} C_{2}$ we devisej a novel double resonance scheme to excite fluorescence. ${ }^{39}$ The approach involves initial excitation of the $(3,0)$ band of the Phillips system $\left(A^{1} \Pi_{u}+X^{1} \Sigma_{g}^{+}\right)$at $771 \mathrm{~nm}$, followed 50 ns later by $404-\mathrm{nm}$ excitation of the $(2,3)$ band of the $c^{1} \Pi_{B}+A^{1} \Pi_{u}$. Fliorescence is detected from the $(2,1)$ band of the $C^{1} \Pi_{B}-A^{1} \Pi_{U}$ transition. This approach yialds a much improved signal-to-nojse ratio compared to simple excitation of and fluorescence detection from the Philiips system. This transition is weak and exhibits a radiative lifetime of $11 \mu \mathrm{s} .{ }^{40}$ Furthermore, fluorescence is in the red where high temperature blackbody radiation is a major source of noise.

A typical example of the temporal behavior of $c_{2}\left(a^{3} \Pi_{u}, v=0\right)$ in the presence of oxygen is shown in Fig. 14. The long time decay exhibits single exponential behavior from which the disappearunce rate of ${ }^{3} C_{2}$ is obtained. The reaction rate constart at a particular temperature is derived by taking the slope from a Stern-Volm $r$ plot of the disappearance :ate versus $\mathrm{O}_{2}$ pressure. Such a plot for a temperature of $886 \mathrm{~K}$ is shown in Fig. 15. Rate constants for $v=0,1,2$ of the ${ }^{3} \mathrm{C}_{2}$ stale were deternined at a number of temperatures. A logarithmic plot of the rate constants versis $1 / T$ is shown in Fig. 16. An excellent $i^{t}$ of wite $"=0$ points to the Arrhenius expression, 
$k(T)=A \exp (-E / R T)$, was obtained with $A=1.49 \pm 0.03 \times 10^{-11} \mathrm{~cm}^{3}$ molecule $e^{-1} \mathrm{~s}^{-1}$ and $E=0.98 \pm 0.02 \mathrm{kcal} / \mathrm{mole}$. The data for the two excited vibrational levels of ${ }^{3} \mathrm{C}_{2}$ clearly do not reflect Arrhenus behavior, although the reaction rates appear to converge with that of $v=0$ at higher temperatures. This behavior is consistent with the fact that at lower terperatures the vibrational relaxation of $c_{2}\left(a^{3} n_{u}, v=1,2\right)$ dominates the kinetics while at elevated temperatures vibraiional relaxalion does not play as significant a role. A model which reproduces the ea:ly temporal behavior of the fluorescence signal (i.e. the risetime) and incorporates the reaction rate, singlet-triplet intersystem crossing rate, the initial relative ${ }^{3} \mathrm{c}_{2} /{ }^{1} \mathrm{c}_{2}$ quantum yields, and vibrational relaxption rates substantiates this argument.

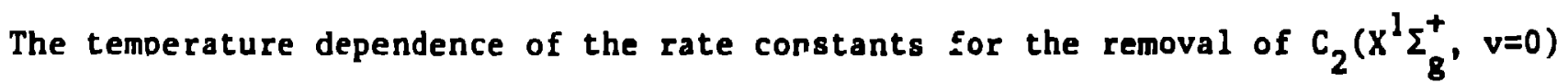
by $\mathrm{O}_{2}$ exhibits essentially the same Arrhenius behavior as the vibrationless triplet state. Previous experiments over the limited temperature range from 300-600 $\mathrm{K}$ were unable to determine unambiguously whether the reaction followed Arrhenius behavior or not. ${ }^{1 / 4}$ Furthermore, the observed Al rhenius behavior was not predicted by a model proposed by other investigators. 17

in order to understand the observed behavior in tie $\mathrm{C}_{2}+\mathrm{O}_{2}$ system, the following kinetic scheme involving reaction and intersystem crossing is considered:

$$
\begin{aligned}
& { }^{1} c_{2}+o_{2} \stackrel{\mathrm{k}_{1}}{\longrightarrow} \text { products } \\
& { }^{3} \mathrm{C}_{2}+\mathrm{o}_{2} \stackrel{\mathrm{k}_{3}}{=} \text { products } \\
& { }^{3} \mathrm{C}_{2}+\mathrm{o}_{2} \frac{\mathrm{k}_{f}}{\mathrm{k}_{r}}{ }^{1} \mathrm{c}_{2}+\mathrm{O}_{2} .
\end{aligned}
$$


Mangir et al. using the method of Luplace transforms have solved the differential equations corresponding to these reactions. ${ }^{17}$ In aduition they showed that at $300 \mathrm{~K}$ the intersystem crossing rate constant was much faster than the reaction rate ronstant. Under these circumstances the observed disappearance rate, $k$ obs fur both ${ }^{1} i_{2}$ and ${ }^{3} c_{2}$ is given by

$$
k_{\text {obs }}=\frac{k_{1}+S k_{3}}{1+S}
$$

where $S$ is the equilibrium constant,

$$
S=\frac{k_{r}}{k_{f}}=\frac{8_{3}}{\mathbf{g}_{1}} \quad \exp \left(\Delta E_{13} / R T\right)
$$

Here $\Delta E_{13}$ is the singlet-triplet energy separation and $g_{3}$ and $g_{1}$ are the degeneracies of the triplet (6) and singlet (1) states, respectivelv. Because S varies substantially over the temperatures employed in the present study, the temperature dependence of the observed disappearance rate constant will be Arrhenius only if $k_{1}=k_{3}$. Intuizively, this could indeed be the case if intersystem crossing (a spin-allowed process for $\mathrm{C}_{2}$ and $\mathrm{O}_{2}$ ) occurs upon long-range interaction, while reaction takes place upon closer approach.

\section{SURMARY}

We have attempted to indicate by way of several examples the ability of laserbased diagnostic techniques to make noninvasive measurements in hostile environments. Using colerent anti-Stokes Raman scattering both majority and ininority species concentrations, as well as temperature, have been 'neasured itl the hol, high-pressure, particle-laden stream of a coal gasifier. In addition, numerous toxic and corrosive elements in the gasifier stream have been identified, but not yet quantified. In 
addition to providing the capability for making analytical determinations, laser techniques have been extensively employed to measure the rates of elementary chemical reactions. Recently, the temperature regime over which such measurements are possible has been expanded. Data dereived from these studies will aid significantly in the modeling of complex systems.

Although much of the laser diagnostic activity to date has involved investigations of the gas phase, significant information concerning heterogeneous phenomena can still be inferred. For instance, gas-solid reactions can manifest themselves as changes in vapor phase composition. Furthermore, in the future we expect expanded studies involving reactions of refractory metals (both atoms and clusters) and additional investigations of processes occurring at interfaces and on surfaces.

\section{ACKNOWLEDGMENTS}

It is a pleasure to acknowledge Drs. David Taylor, Richari Oldenborg, Steven Baughcum, Thomas Lorce, David Cremers, Leon Radziemski, and Harold Dilworth for their outstanding efforts in carrying out the research described here. I alsu wish to thank Mr. Monty Ferris for his expert assistance in carrying out numerous field tests. The author is also indebted to the Norgantown Energy Technology Center for sponsoring and participating in the CARS and LIBS programs. 


\section{References:}

1. ․ R. Andersion, L. J. Dr:ker, and A. J. Kotlar, Combust. Fl ame 48, 179 (1982).

2. P. A. Bonczyk and J. A. Shirley, Combust. Flame 34, 253 (1979).

3. A. P. Barcnauski and J. R. McDonald, Appl. Optics 16, 1897 (1977).

4. A. P. Baronalvski and J. R. McDonald, J. Chem. Phys. 66, 3300 (1977).

5. L. A. Rahn, L. J. Zych, and P. L. Mattern, Optics Commun. 30, 249 (1979).

6. L. E. Harris, Chem. Phys. Lett. 93, 335 (1982).

i. R. J. Hall, Combust. Flame $\underline{35}, 47$ (1979).

8. J. H. Bechte:l and R. E. Teets, Appl. Optics $\underline{18}, 4138$ (1979).

9. D. Klick, K. A. Marko, and L. Rimai, Appl. Optics 20, 1178 (1981).

10. I. A. Stenhouse, D. R. Williams, J. B. Cole, and M. D. Swords, Appl. Optics 18, 3819 (1979).

11. W. J. Van den Hock and J. A. Visser, J. Phys. D: Appl. Phys. 14, 1613 (1981).

12. F. C. Jahodia, SPIE 288,518 (1981).

13. D. J. Taylor, "CARS Concentration and Temperature Measurements in Coal Gasifiers," Appl. Optics (submitted for publication).

14. W. M. Pitts, L. Pasternack, and J. R. McDonald, Cram. Phys. 68, 417 (1982).

15. H. H. Nelson, I. Pasternack, J. R. Eyler, and J. R. McDonald, Chem. Phys. 60, 231 (1981).

16. M. N. R. Ashfold, M. A. Fullstone, G. Hanccik, and G. W. Ketley, Chem. Phys. 55, $245(1981)$.

17. M. S. Mangir, H. Reisler, and C. Wittig, J. Chem. Phys. 73, 829 (1980).

18. H. Reisler, M. Mangir, and C. Wittig, Chem. Phys, 47, 49 (1980).

19. H. Reisler, M. S. Mangir, and C. Wittig, J. Chem. Phys, 73, 2280 (1980).

20. J. E. Butler, L. P. Goss, M. C. Lin, and J. W. Hudgens, Chem. Phys. LetL. 63, 104 (1979).

21. C. S. Gudeman, M. H. Begeman, J. Pfaff, and R. J. Saykally, Pliys. Rev. Lall. 50, 727 (1983).

22. M. A. Duncan, V. M. Biprbanm, G. B. Ellison, and S. R. Leone, J. Chem. Phys. 79. $5448(1983)$.

23. U. R. Guyer, L. Hüwel, and S. R. Leone, J. Chem. Phys. 79, 1255 (1983). 
24. J. B. Hopkins, P. R. R. Langridge-Smith, M. D. Morse, and R. E. Smalley, J. Chem. Phys. 78, 1627 (1983).

25. M. D. Morse, J. B. Hopkins, P. R. K. Langridge-Smith, and R. E. Smalley, J. Chem. Phys. 79, 5316 (1983).

26. D. E. Powers, S. G. Hansen, M. E. Geusic, D. L. Michalopoulos, and R. E. Smalley, J. Chem. Phys. $\underline{78}, 2866$ (1983).

27. L. J. Radziemski and T. R. Loree, Plasma Chem. Plasma Pros. 1, 281 (1981).

28. L. J. Radziemski, T. R. Loree, D. A. Cremers, and H. M. Nelson, Anal. Chem. 55, 1246 (1983).

29. A. C. Eckbreth, tppl. Phys. Lett. 32, 421 (1978).

30. J. J. Valentini, Spectromet ic Techniques 4, Academic Press, New York (1984).

31. A. C. Eckb: ech and R. J. Hall, Combust. Flame 36, 87 (1979).

32. A. C. Eckbreth and R. J. Hall, NBS Mater. Res. Symp. Charact. High Temp. Vapors Gases, 10th, Gaithersbur\&, Maryland (1978).

33. R. J. Hall, J. F. Verdieck, and A. C. Eckbreth, Optics Cumnun. 35, 69 (1980).

34. E. F. Runger, Bonfiglio, and F. R. Bryan, Spectrochim. Acta 22, 1678 (1966).

35. R. H. Scott and A. Strasheim, Spectrochim. Act.a 25B, 311 (1970).

36. T. Ozaki, T. Takahashi, Y. Iwai, K. Gunji, and E. Sodo, Tetsu To Hagana 68, $872(1982)$.

37. W. Felier, A. Fontijn, II. N. Volltraner, and D. R. Voohes, Rev. Sci. Instrum. $195(1980)$.

38. K. P. Huber and G. Herzberg, Molecular Spectra and Molecular Structure IV. Constants of Diatomic Nolecules, Van Nostrand keinhold, New York, 1979.

39. S. L. Baughicum and R. C. Oldenborg, "A New High Temperature Diagnostic for $\mathrm{C}_{2}\left(X^{1} \Sigma_{g}^{+}\right)$to Study the Reuction Kinetics and Intersystem Crossing Rates of $\mathrm{C}_{2}\left(\mathrm{X}^{1} \Sigma_{8}^{+}\right)$and $\mathrm{C}_{2}\left(\mathrm{a}^{3} \Pi_{u}\right)$ with $\mathrm{O}_{2}$ in the 298-1300 K Temperature Range," Western states Section Meeting of the Combistion Instltute, October 17-18, 1983, Los Angeles, California.

40. P. Erman, D. L. Lambert, M. Larsson, and Mannfors, Astrophys. J. 253, 983 (1982). 


\section{Figure Captions:}

1. Schematic of a typical apparatus for CARS measurements. A portion of the frequency-doubled output (532 nm) of a Nd:YAG laser provides the pump beam $\left(v_{p}\right)$, while the remainder pumps a dye laser which provides the Stokes bean $\left(v_{s}\right)$.

2. The CARS signal of $\mathrm{N}_{2}$ present in the METC stirred, fixed-bed coal gasifier. The spectrum on the right was obtained by scanning the tunable dye laser over the entire band contour. The signal on the left corresponds to the peak CARS signal as a function of time.

3. The CARS signal of CO present in the METC coal gasifier. The spectrum on the right is a scan over the entire band contour, while the signal on the left was obtained by monitoring the peak CARS signal as a function of time.

4. The CARS spectrum of $\mathrm{H}_{2} \mathrm{~S}$ present in the METC coal gasifier.

5. The CARS spectrum of $\mathrm{CH}_{4}$ present in the METC coal gasifier. The smaller red-shifted feature appears to be a hot-band transition.

6. Apparatus for performing time-resolved laser-induced breakdown spectroscopy. The time-gated diode array allows spectral recording to be delayed with respect to the onset of breakdown. The signal-to-noise ratio can be improved using this procedure.

7. A typical LIBS spectrum obtained from the output gas stream of the METC coal gasifier showing the trace elements $\mathrm{Al}, \mathrm{Cu}, \mathrm{K}, \mathrm{Pb}$, and $\mathrm{S}$.

8. A LIBS spectrum from the process stream of the METC coal gasifier showing the trace elements $\mathrm{Al}, \mathrm{Ba}, \mathrm{C} \varepsilon, \mathrm{Cu}, \mathrm{S}$, and Se.

9. Apparatus for LIBS elemental analysis of solid steel samples. A spark is generated by a Nl:YAG laser and the emission is dispersed by scanning monochromator. 
10. Apparatus for elemental analysis of solid steel samples using laser ablation to produce metal particles which are entrained in an argon carrier gas and introdured into an inductively-coupled plasma (ICP). The spectral emission from the ICP is analyzed by a polychromator capable of monitoring several elements simultaneously.

11. Calibration curve for silicon using the laser ablation/ICP techniques. A comparable calibration curve for carbon could not be obtained due to impurities in the ICP carrier gas.

12. Apparatus used to measure the rates of elementary chemical reactions. The excimer laser produces free radicals by laser photolysis of suitable precursor molecules. The tunable dye laser excites fluorescence in the free radicals. A variable delay between photolysis and probe laser allows temporal information to be obtained.

13. High-temperature cell used to study the temperature dependence of the reastion rates of transient species.

14. Typical signal of the time dependence of the disappearance of $\mathrm{C}_{2}\left(a^{3}{ }_{\mathrm{II}}, v=0\right)$ in the presence of a fixed pressure of $\mathrm{O}_{2}$.

15. The rate of $C_{2}\left(a^{3} \Pi_{u}\right)$ disappearance as a function of $O_{2}$ pressure at $886 \mathrm{~K}$. The slope of the line yields the reaction rate constant at this tempecature.

16. The temperature dependence of the rate constarit for the reaction of $c_{2}\left(a^{3} \Pi_{u}\right)$ with $\mathrm{O}_{2}$. The reaction of the $v=0$ level exhibits Arrhenius behavior over the temperature range from 298-1300 K, while the $v=1,2$ levels do not. 


\section{CARS MONITORING SYSTEM}

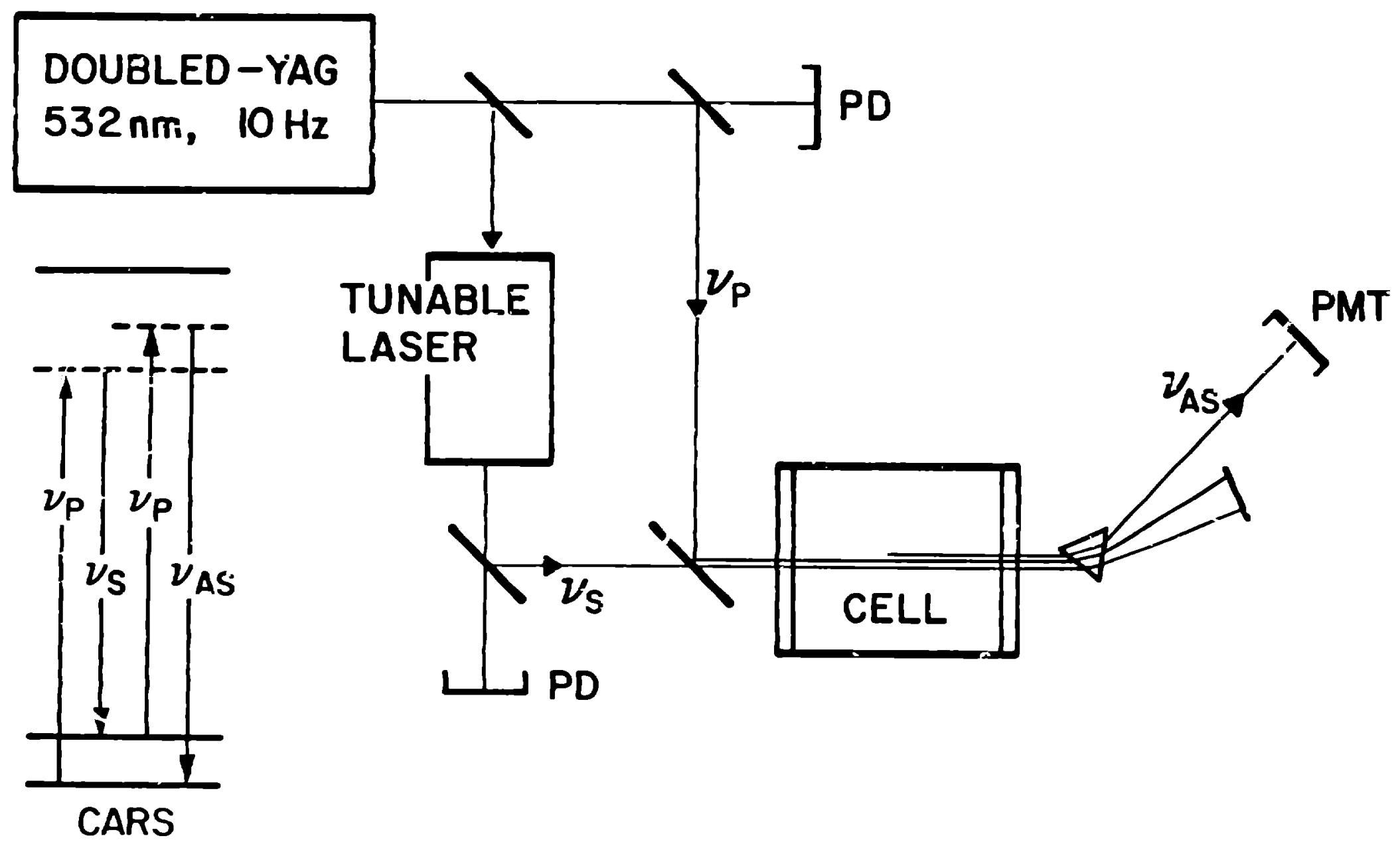




\section{$\mathrm{N}_{2}$ CARS SIGNALS OBTAINED ON THE METC FIXED-BED COAL GASIFIER}
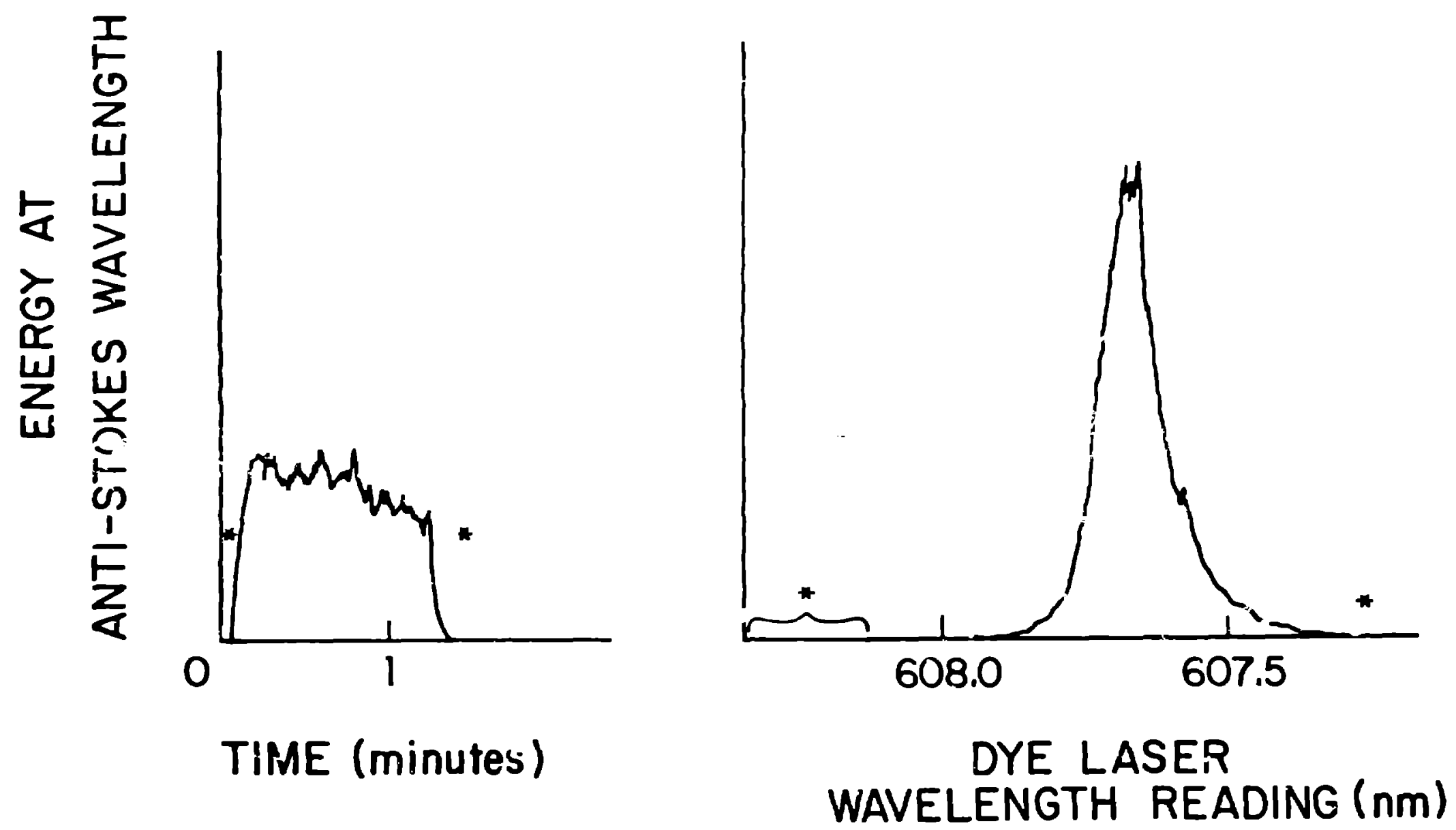
CO CARS SIGNAL OBTAINED ON THE METC FIXED-BED COAL GASIFIER
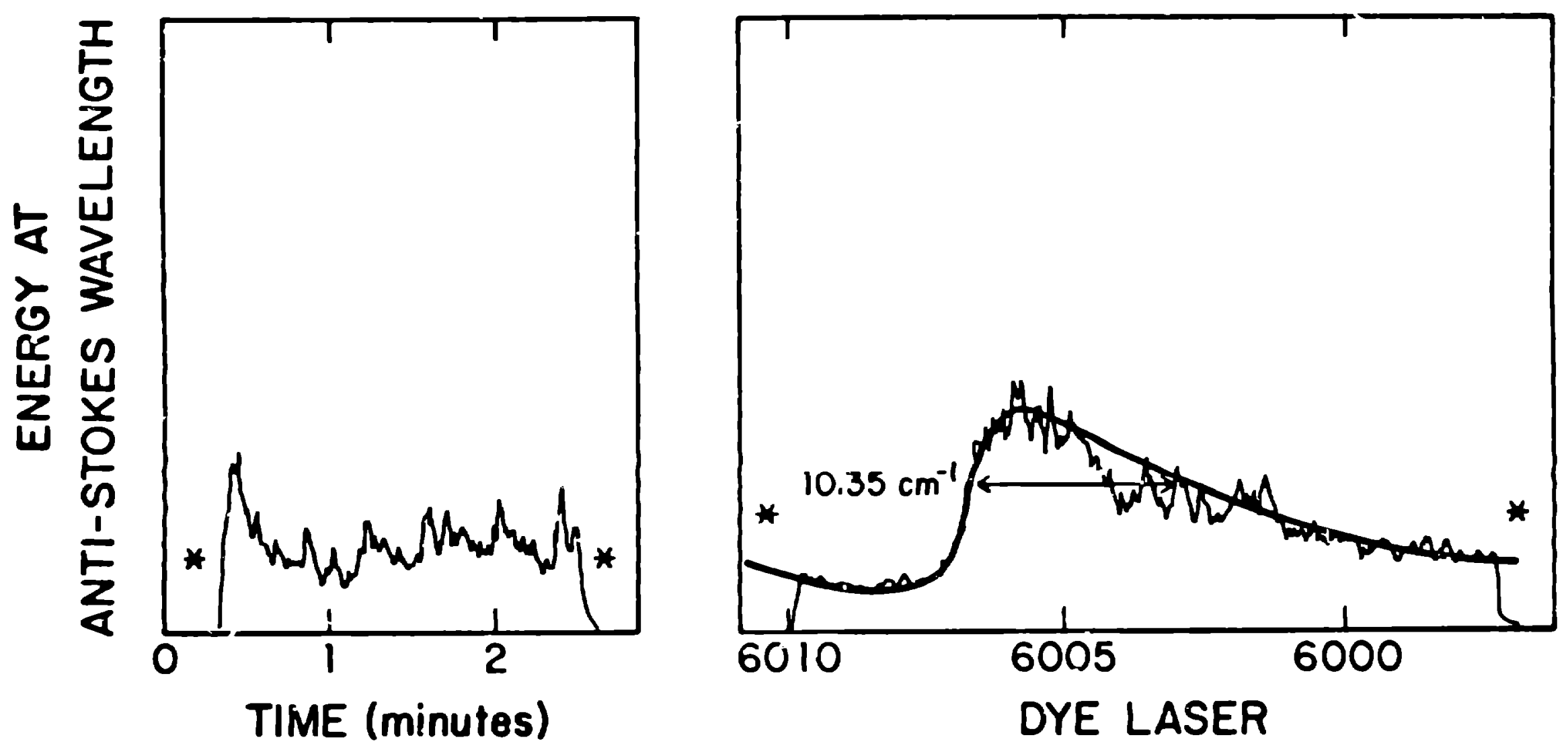

WAVELENGTH READING ( $(\AA)$ 


\section{$\mathrm{H}_{2} \mathrm{~S}$ CARS SIGNAL OBTAINED ON THE METC FIXED-BED COAL GASIFIER}

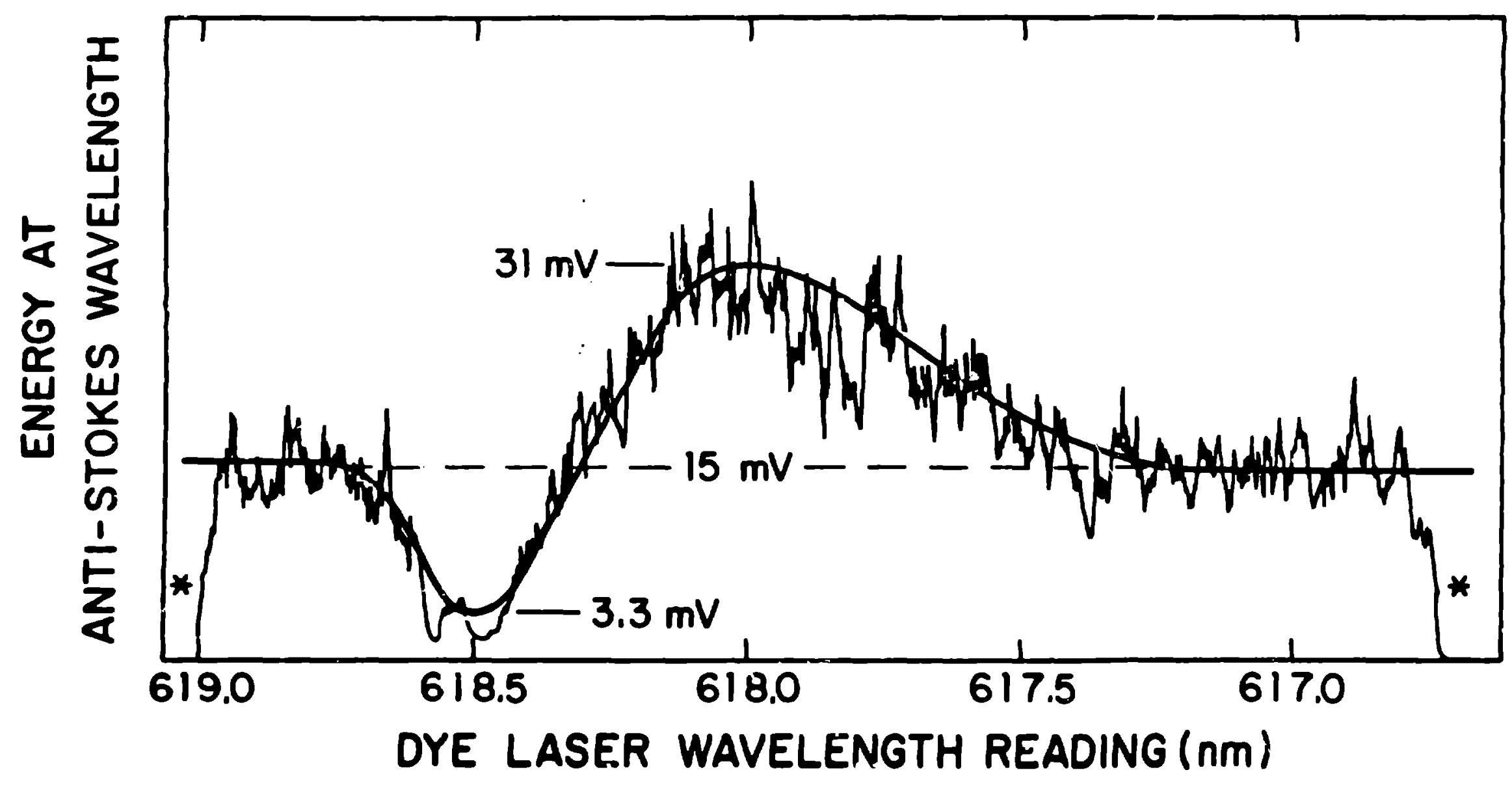


$\mathrm{CH}_{4}$ CARS SIGNAL ON METC COAL GASIFIER

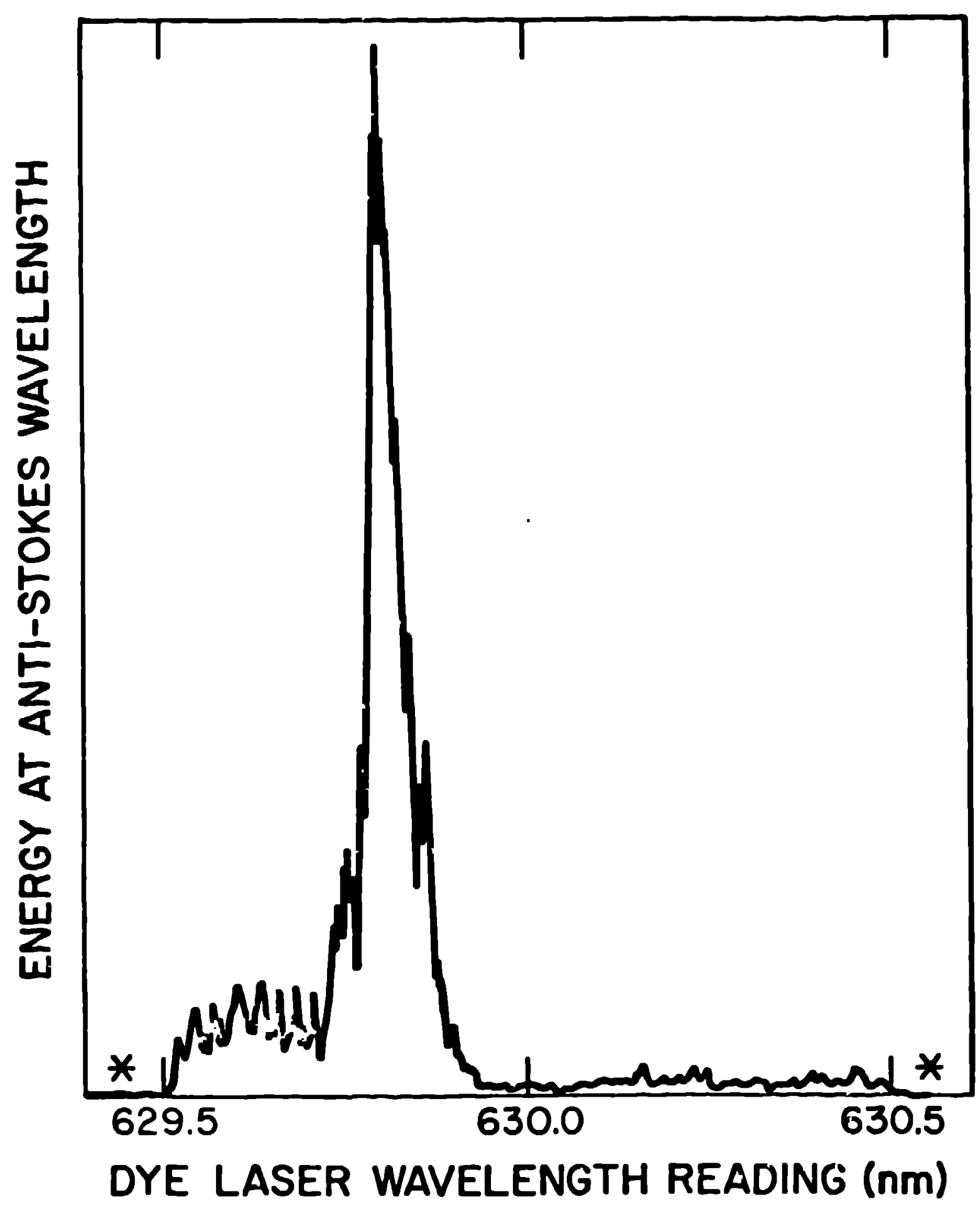




\section{APPARATUS FOR TIME-RESOLVED LASER-INDUCED BREAKDOWN SPECTROSCOPY}

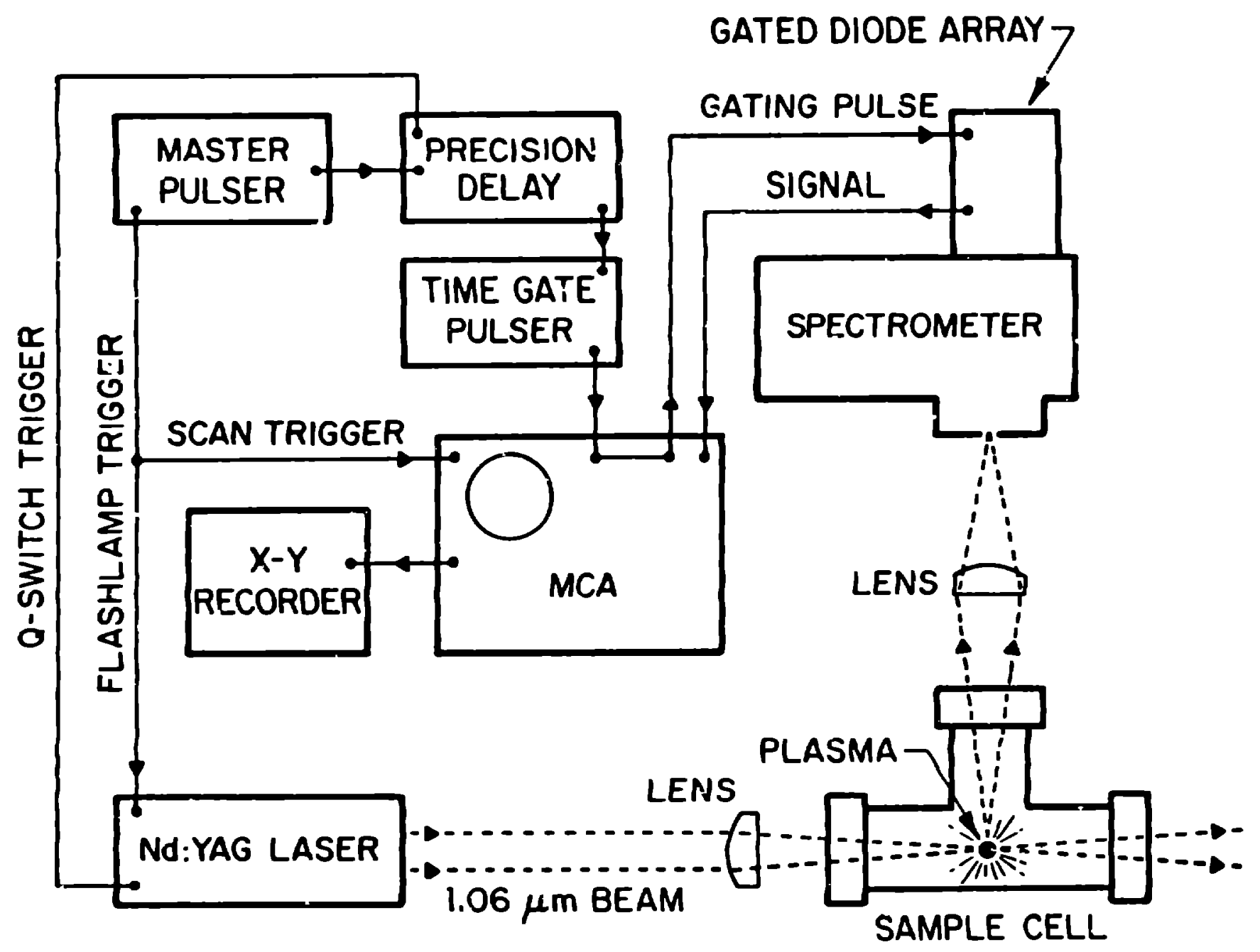

CHM-VG-2191 


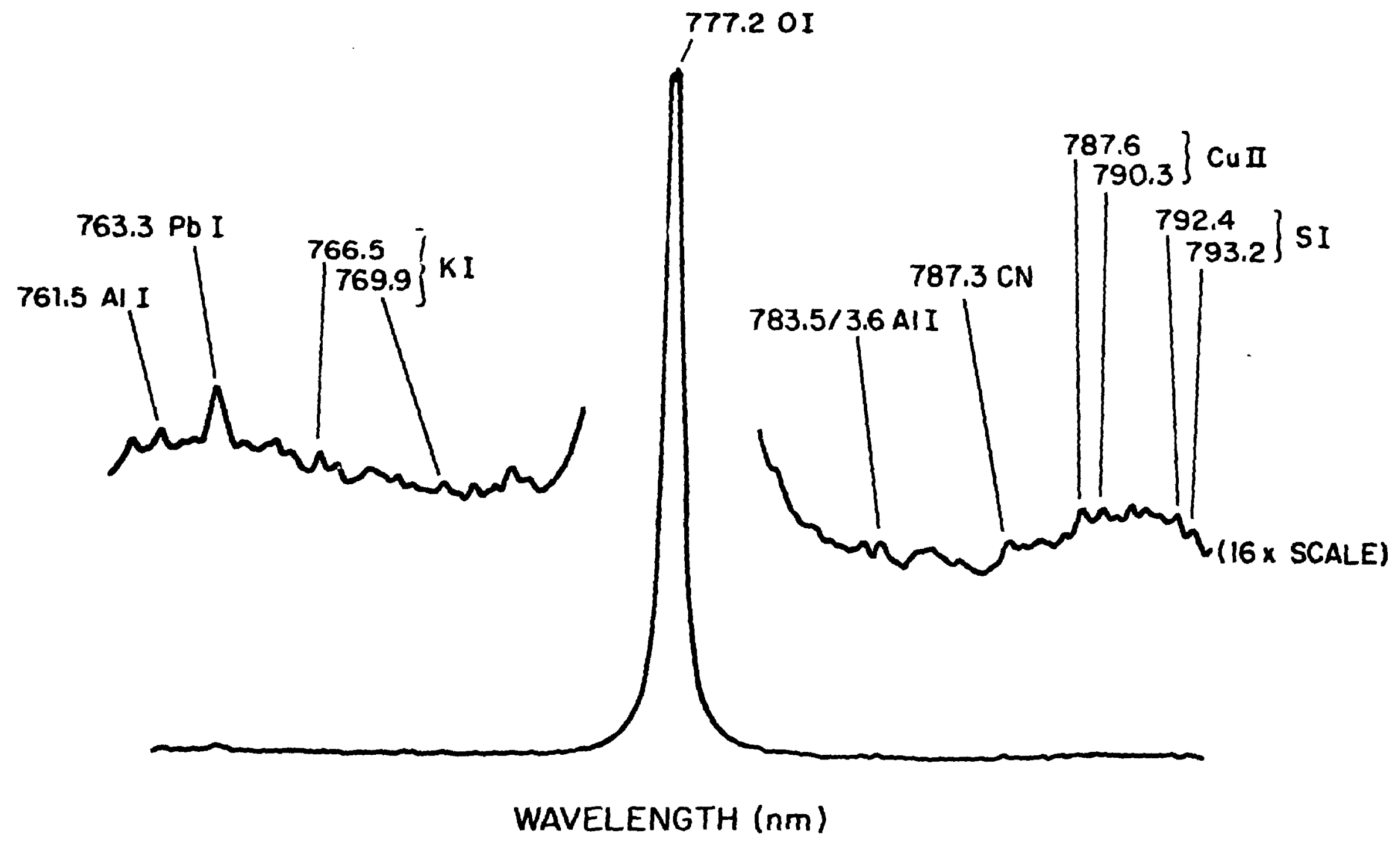

CHM-VG - 3396 


\section{GASIFIER LIBS \\ $(770-820 \mathrm{~nm})$}

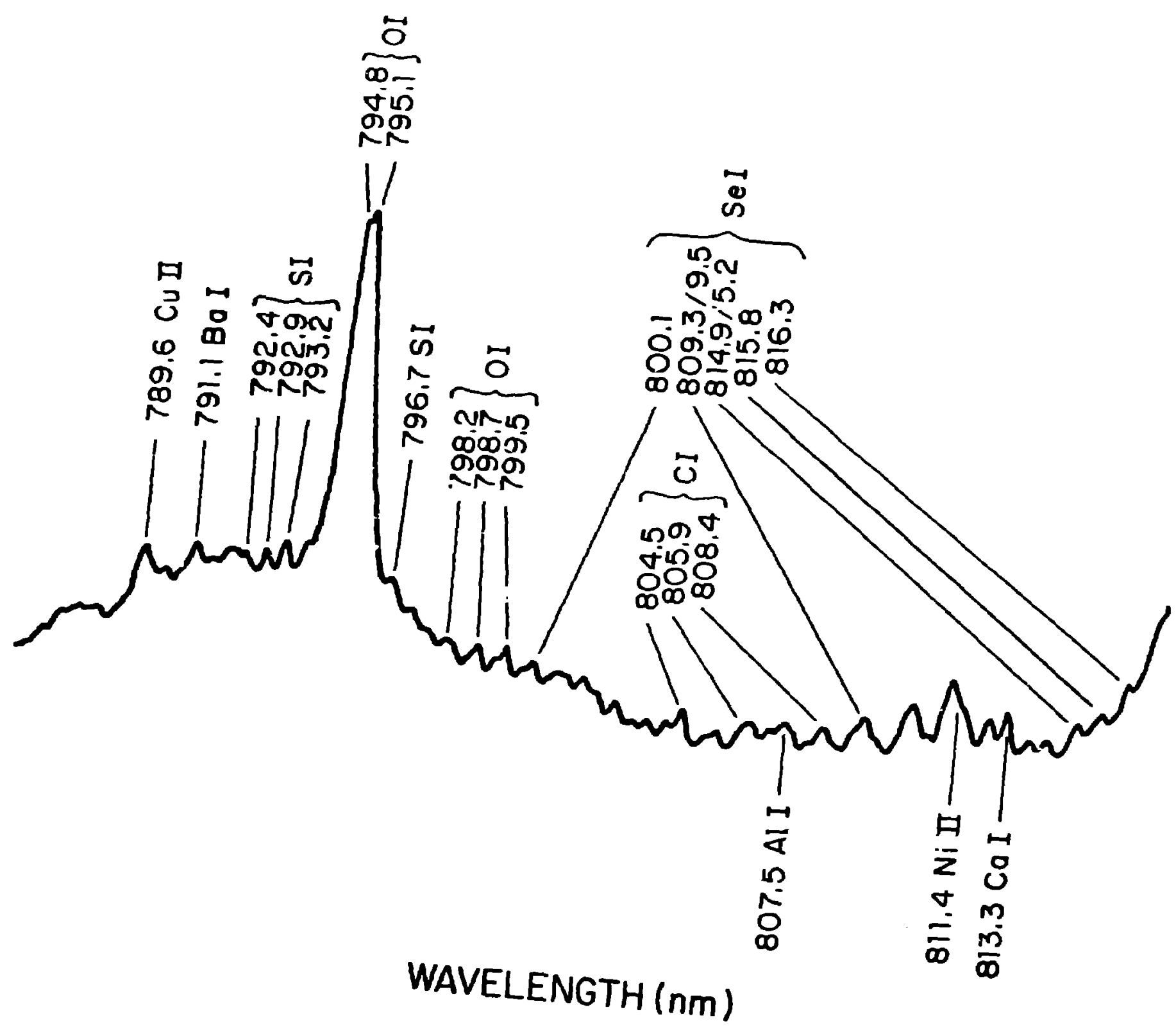

CHM-VG - 3500 


\section{DIRECT SPARK ANALYSIS: METHOD OF DATA COLLECTION}

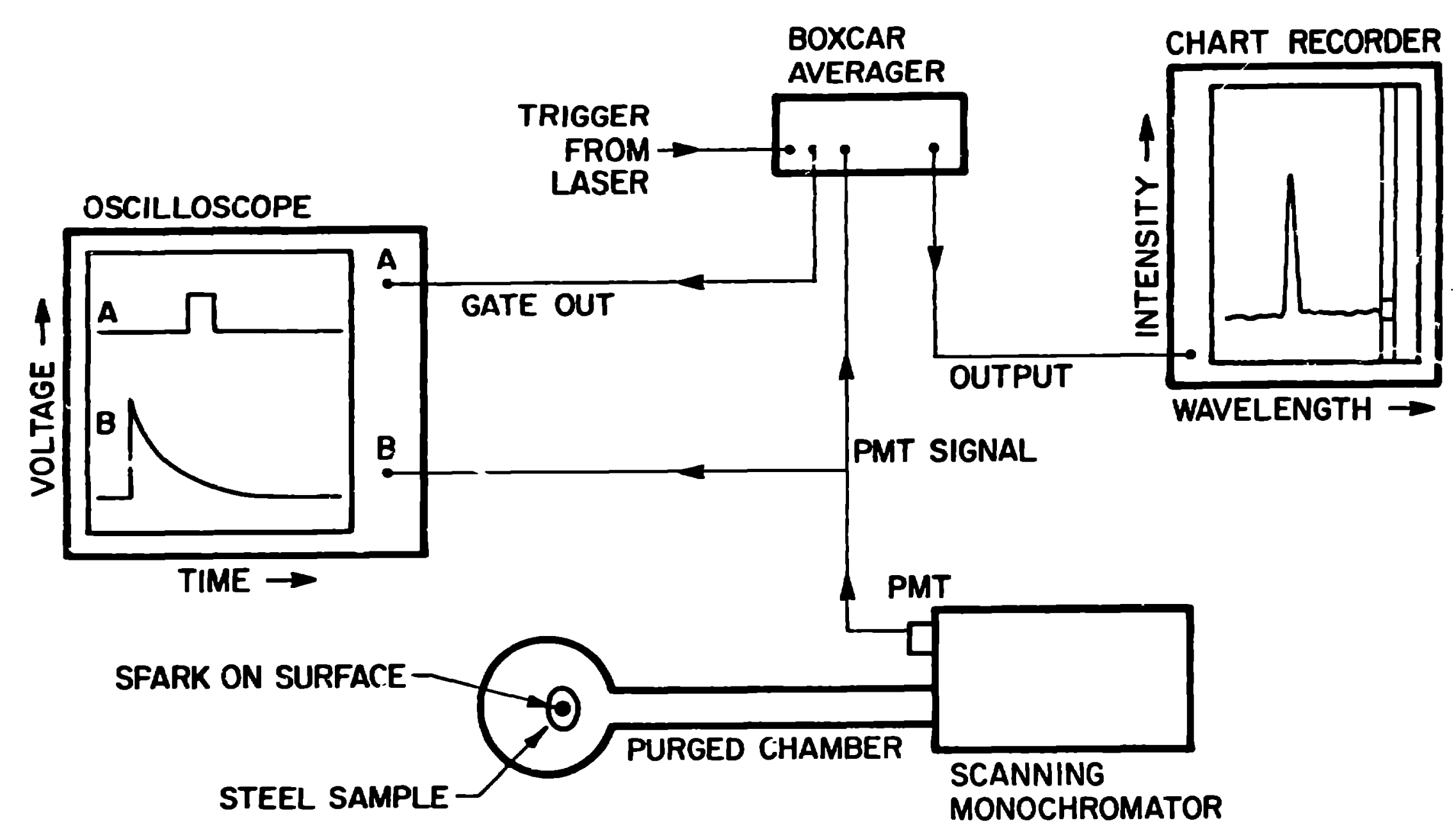




\section{SAMPLE ONLY METHOD: ICP ANALYSIS OF METAL PARTICLES}

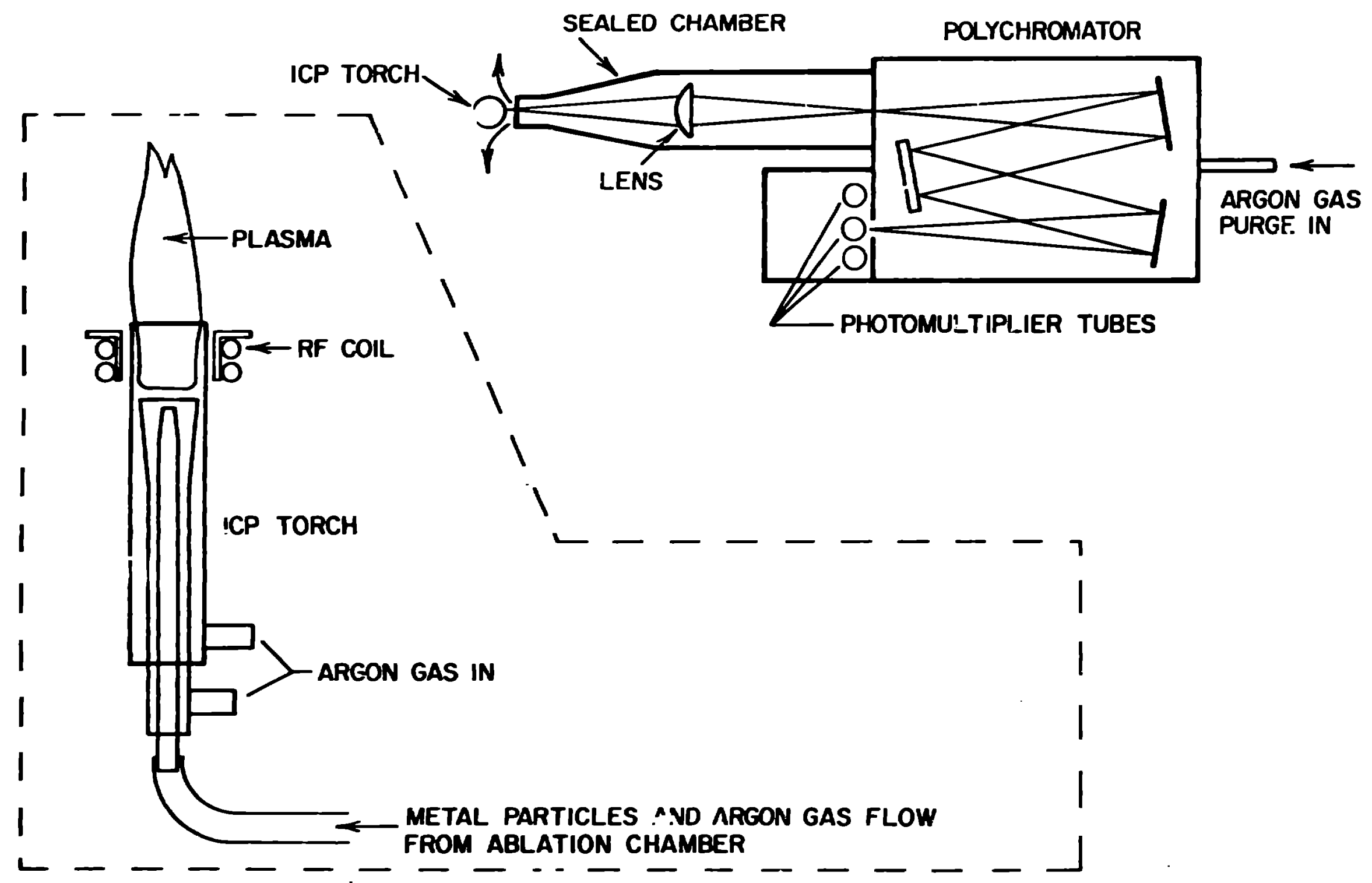




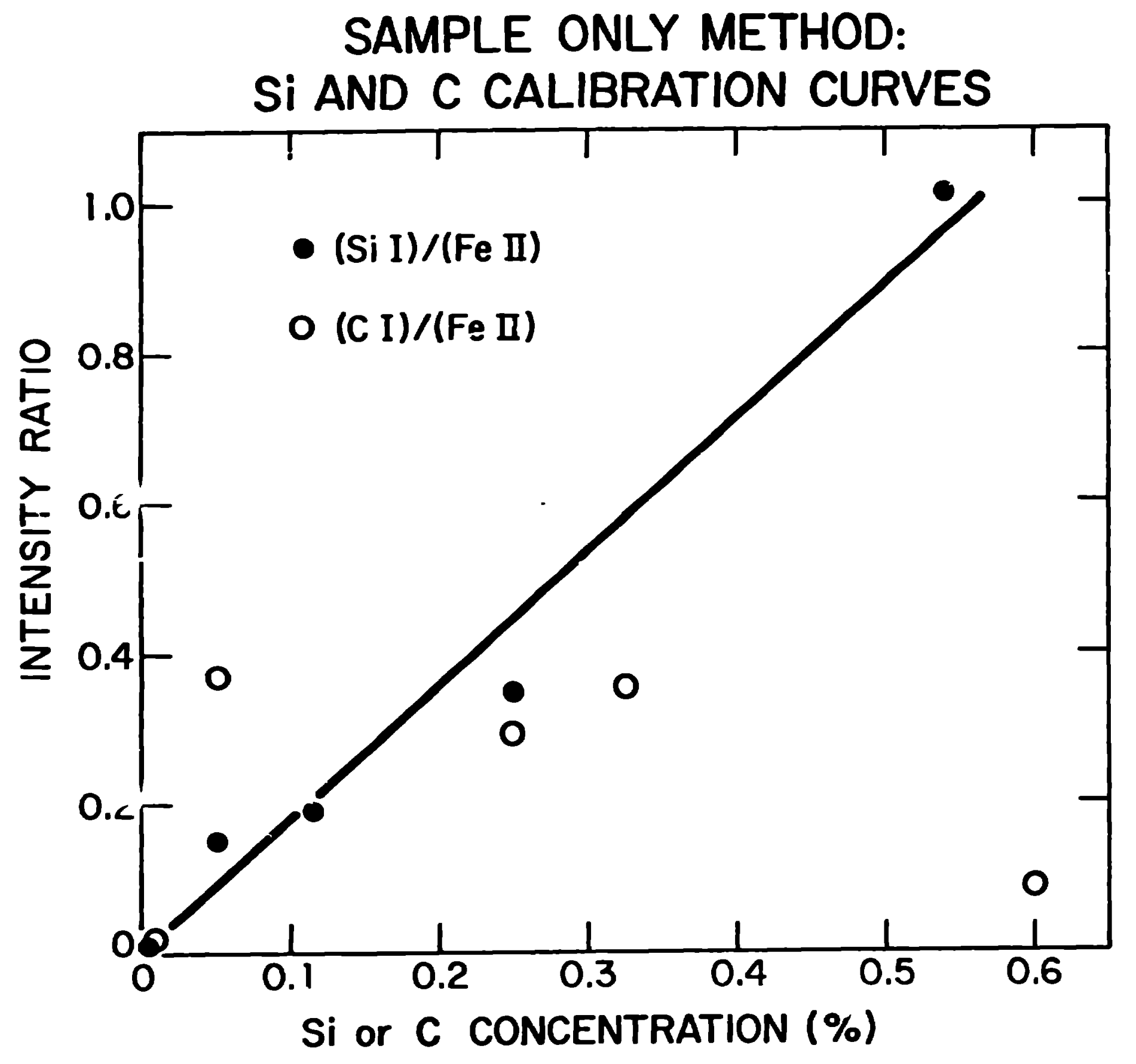

CHM-VG-3186 


\section{LASER-INDUCED FLUORESCENCE EXPERIMENTAL APPARATUS}

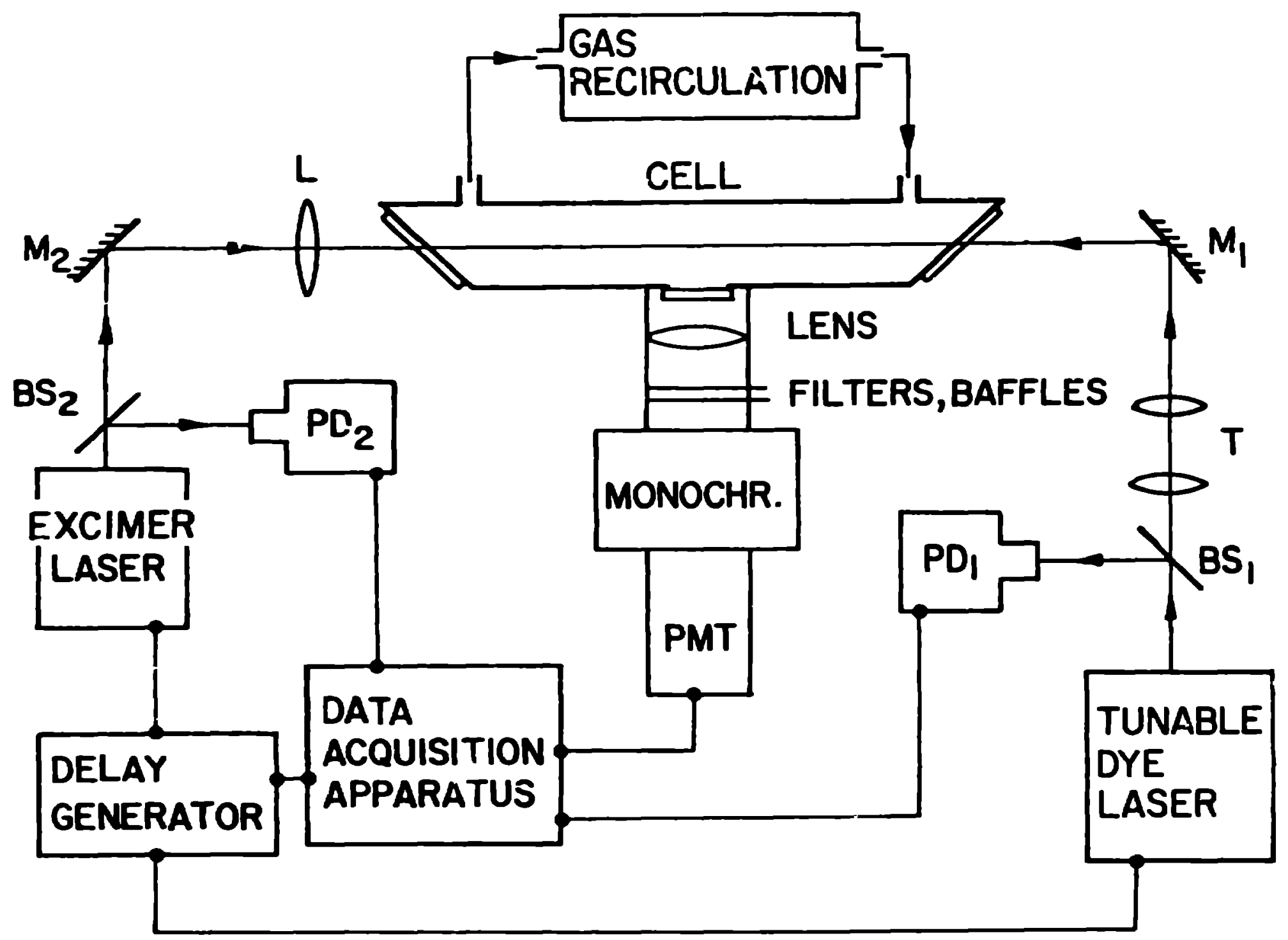


LASER-INDUCED FLUORESCENCE COMBUSTION CELL $\left(25-1500^{\circ} \mathrm{C}\right)$

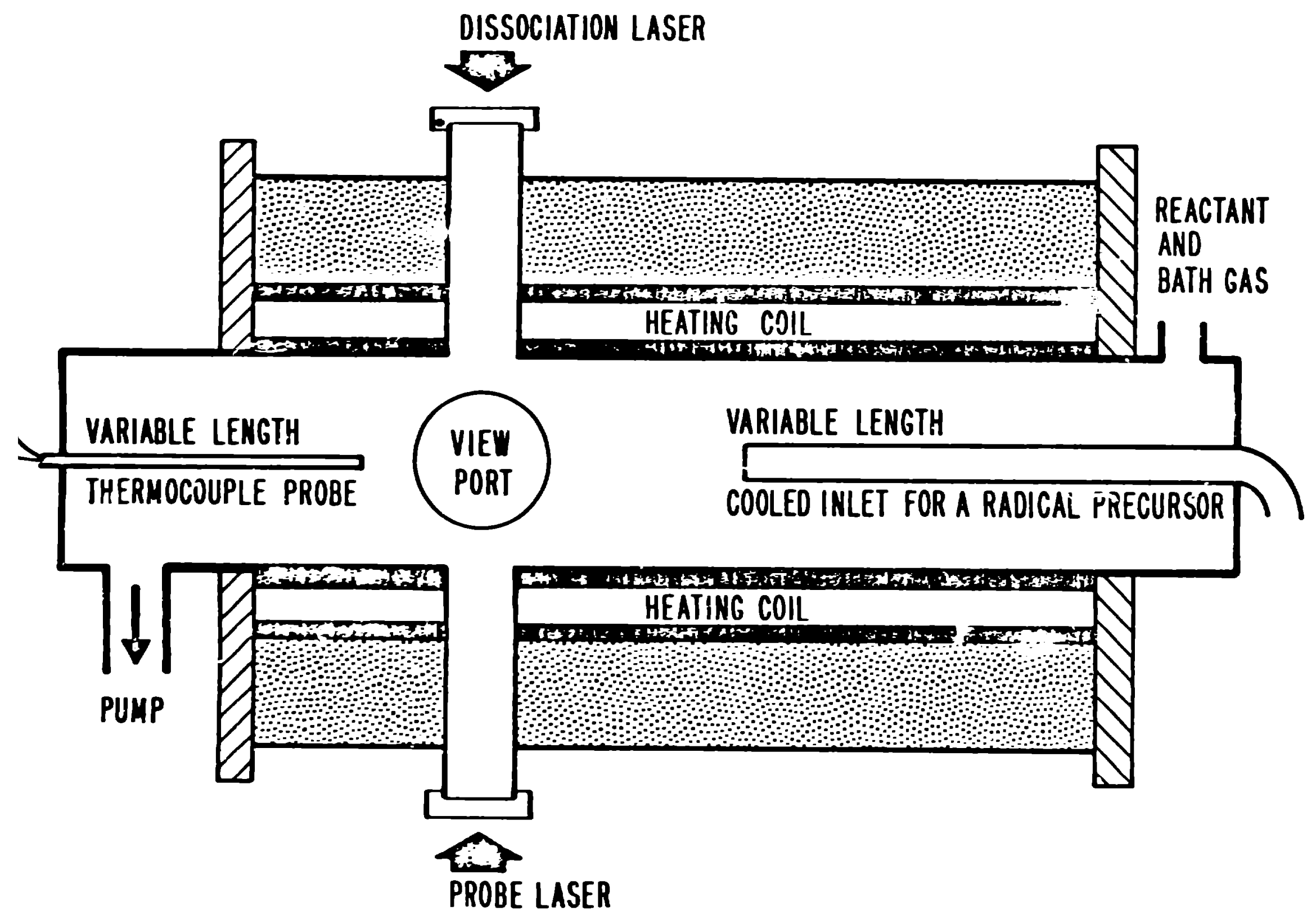




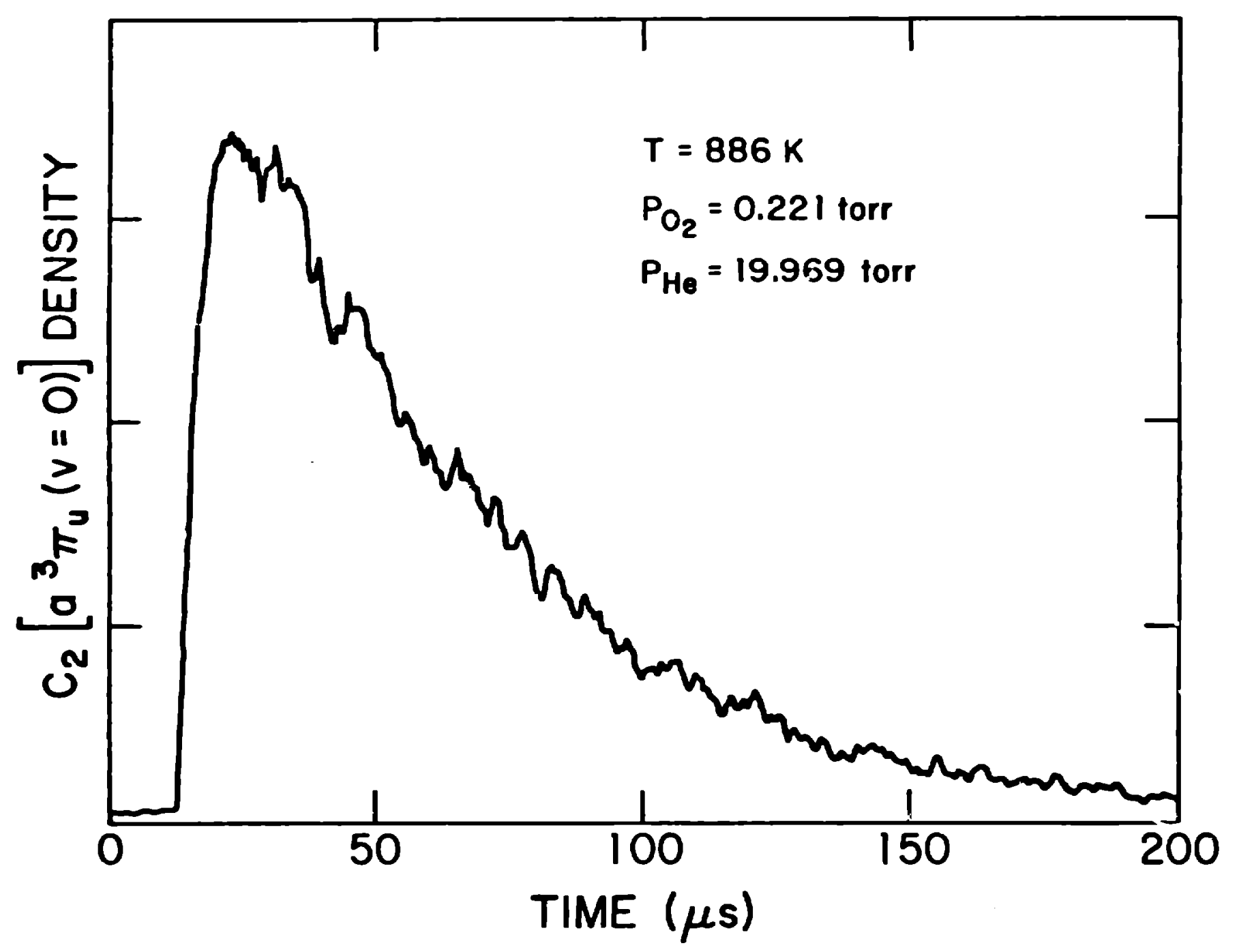

CHM-VG-17 19 


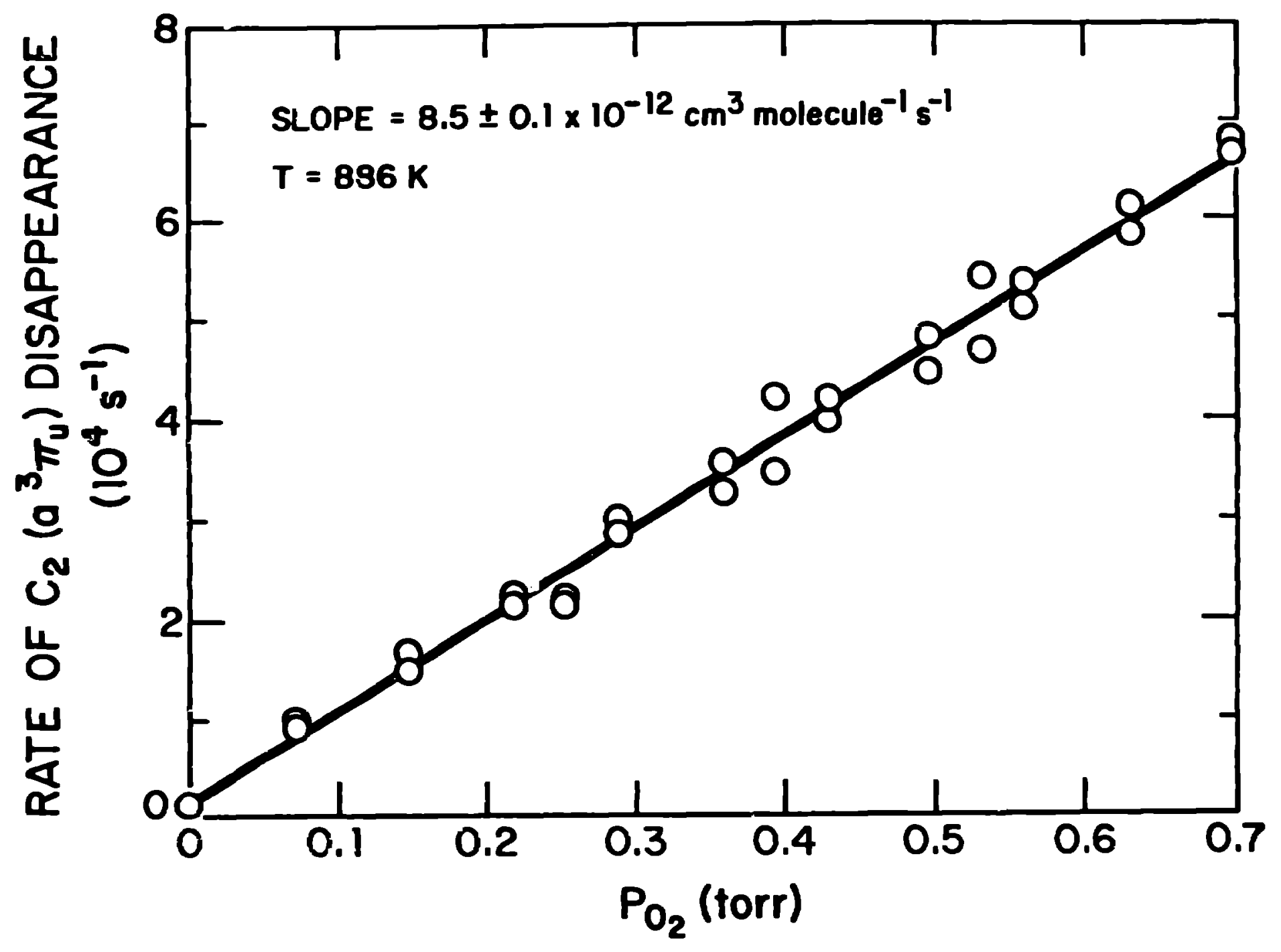




\section{DISAPPEARANCE OF $\mathrm{C}_{2}\left(a^{3} \pi_{u}\right)$ WITH $\mathrm{O}_{2}$}

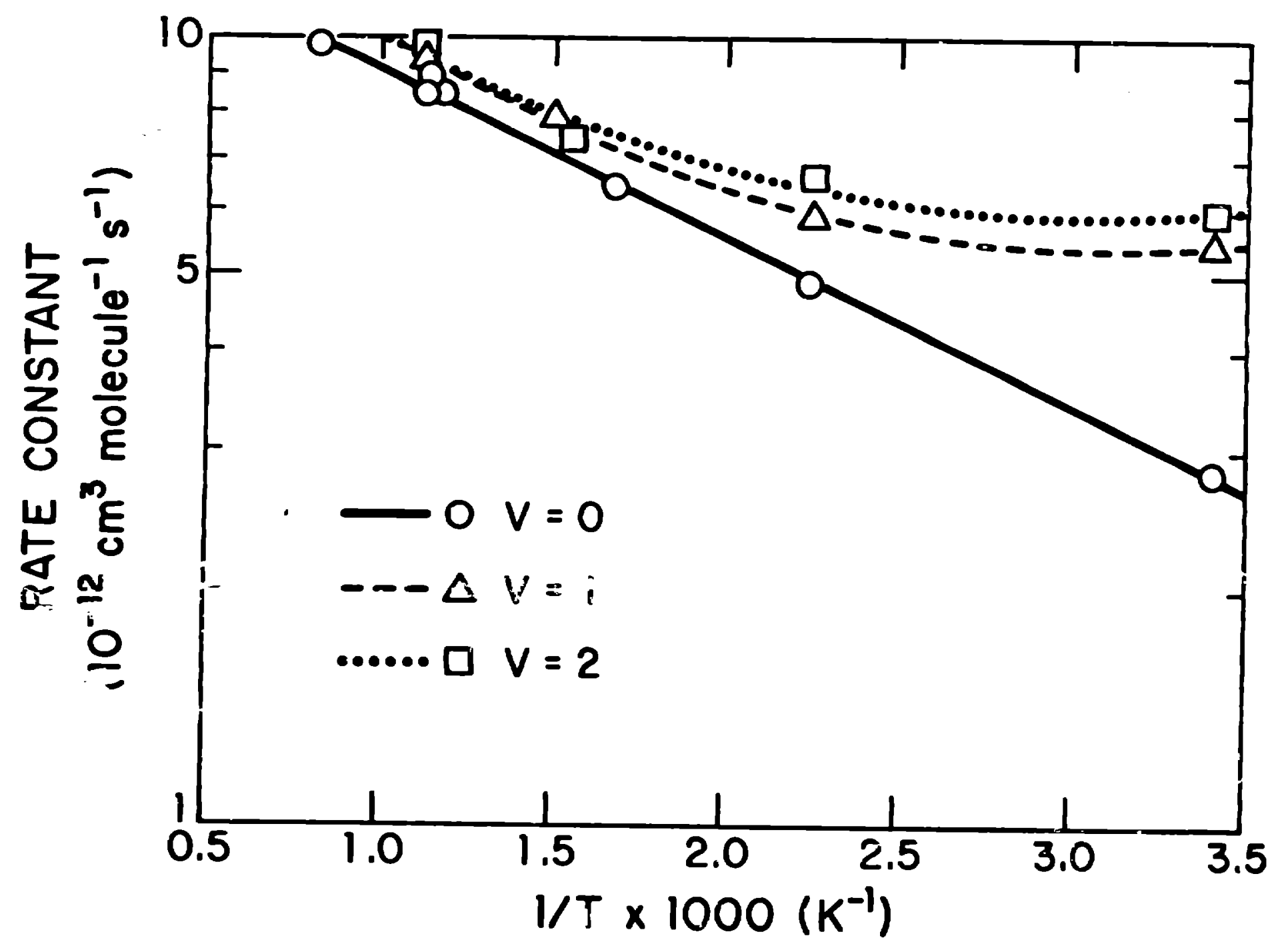

